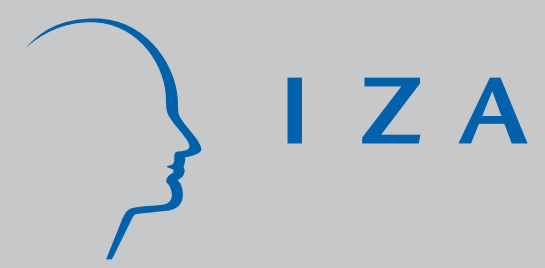

IZA DP No. 6488

Asymmetric Labor Market Institutions in the EMU and the Volatility of Inflation and Unemployment Differentials

Mirko Abbritti

Andreas I. Mueller

April 2012

Forschungsinstitut zur Zukunft der Arbeit Institute for the Study of Labor 


\title{
Asymmetric Labor Market Institutions in the EMU and the Volatility of Inflation and Unemployment Differentials
}

\author{
Mirko Abbritti \\ Universidad de Navarra \\ Andreas I. Mueller \\ Columbia University \\ and IZA
}

Discussion Paper No. 6488

April 2012

IZA

P.O. Box 7240

53072 Bonn

Germany

Phone: +49-228-3894-0

Fax: +49-228-3894-180

E-mail: iza@iza.org

\begin{abstract}
Any opinions expressed here are those of the author(s) and not those of IZA. Research published in this series may include views on policy, but the institute itself takes no institutional policy positions.

The Institute for the Study of Labor (IZA) in Bonn is a local and virtual international research center and a place of communication between science, politics and business. IZA is an independent nonprofit organization supported by Deutsche Post Foundation. The center is associated with the University of Bonn and offers a stimulating research environment through its international network, workshops and conferences, data service, project support, research visits and doctoral program. IZA engages in (i) original and internationally competitive research in all fields of labor economics, (ii) development of policy concepts, and (iii) dissemination of research results and concepts to the interested public.
\end{abstract}

IZA Discussion Papers often represent preliminary work and are circulated to encourage discussion. Citation of such a paper should account for its provisional character. A revised version may be available directly from the author. 


\title{
ABSTRACT
}

\section{Asymmetric Labor Market Institutions in the EMU and the Volatility of Inflation and Unemployment Differentials ${ }^{*}$}

\begin{abstract}
How does the asymmetry of labor market institutions affect the adjustment of a currency union to shocks? To answer this question, this paper sets up a dynamic currency union model with monopolistic competition and sticky prices, hiring frictions and real wage rigidities. In our analysis, we focus on the differentials in inflation and unemployment between countries, as they directly reflect how the currency union responds to shocks. We highlight the following three results: First, we show that it is important to distinguish between different labor market rigidities as they have opposite effects on inflation and unemployment differentials. Second, we find that asymmetries in labor market structures tend to increase the volatility of both inflation and unemployment differentials. Finally, we show that it is important to take into account the interaction between different types of labor market rigidities. Overall, our results suggest that asymmetries in labor market structures worsen the adjustment of a currency union to shocks.
\end{abstract}

JEL Classification: E32, E52, F41

Keywords: currency union, labor market frictions, real wage rigidities, unemployment, sticky prices, inflation differentials

Corresponding author:

Andreas I. Mueller

Columbia Business School

824 Uris Hall

3022 Broadway

New York, NY 10027

USA

E-mail: amueller@columbia.edu

\footnotetext{
*We are very grateful to Charles Wyplosz, Cedric Tille, Pierpaolo Benigno, Lars Calmfors, Per Krusell, John Hassler, Ester Faia, Antonio Moreno, Stephan Fahr, Stefano Manzocchi, Andrea Boitani, Mirella Damiani, Sebastian Weber, Leo de Haan, Thórarinn G. Pétursson, René Kallestrup and seminar participants at LUISS, GIIS Geneva, the University of Perugia, the Central Bank of Iceland, the IIES Stockholm, the ECB, the ASSET conference 2008, the EEA 2008, the Bank of Italy and the DNB for very helpful comments and ideas. Mirko Abbritti gratefully acknowledges financial support by Fondazione Cassa di Risparmio di Perugia and the Graduate Institute, Geneva for support during his graduate studies. Andreas Mueller thanks the Central Bank of Iceland for the hospitality during his summer internships and the IIES Stockholm for support during his graduate studies. He also gratefully acknowledges financial support from the Handelsbanken's Research Foundations.
} 


\section{Introduction}

Recent empirical evidence shows that inflation and output growth differentials among Euro Area countries are rather sizeable and very persistent over time ${ }^{1}$. This evidence has attracted substantial public attention, because it suggests that the adjustment mechanism in the single currency area may not be working efficiently. Labor market rigidities are often blamed as one of the potential causes behind the asymmetric adjustment of member countries to economic shocks. The received wisdom is that there is a "need for more flexible labor markets in the context of the EU, particularly at the national and regional levels" (ECB Monthly Bulletin, May 2005, p. 71) without specifying what labor market flexibility means.

Euro Area countries are characterized by heavily regulated labor markets, generous unemployment benefit systems and high unemployment. Looking only at the European aggregate, however, can be misleading. As documented by Blanchard (2006), Nickell (1997) and Nickell et al. (2001), labor market institutions vary considerably across EMU member countries. For example, employment protection legislation is extremely tight in countries like Italy, Portugal, France and Spain, but very loose in Ireland. These authors also document large heterogeneity in the degree of wage rigidity, the degree of unionization and in the generosity of the unemployment benefit systems.

The aim of the present paper is to analyze how asymmetric labor market institutions affect the volatility of inflation and unemployment differentials in a currency union. For this purpose, we set up a dynamic currency union model that combines three key ingredients: (i) monopolistic competition and nominal rigidities in the goods market, which serve to give a role to monetary policy; (ii) hiring frictions in the labor market, which generate involuntary unemployment; (iii) real wage rigidities, which hinder wage adjustments and shift the labor market adjustment from prices to quantities. We build on Blanchard and Galí (2010) and integrate labor market frictions into our currency union model by assuming the presence of hiring costs, which increase in the degree of labor market tightness. Real wage rigidities are introduced, following much of the literature, by employing a version of Hall's (2005) notion of the wage norm.

To carry out our analysis, we focus on two types of labor market rigidities, Unemployment Rigidities (UR) and Real Wage Rigidities (RWR). The former capture institutions such as employment protection legislation, hiring costs and the matching technology that limit the flows in and out of unemployment, whereas the latter capture the institutions that influence the responsiveness of real wages to economic activity. ${ }^{2}$ We highlight three results: First, we

\footnotetext{
${ }^{1}$ See, e.g., ECB (2003, 2005), Angeloni and Ehrmann (2004), Benalal et al. (2006) for some evidence on inflation and output differentials and for analyses of the potential causes and policy implications.

${ }^{2}$ See Abbritti and Weber (2010) for some evidence on the importance of unemployment rigidities and real
} 
show that it is important to distinguish between these two types of rigidities as they have opposite effects on the volatilities of inflation and unemployment differentials. Unemployment rigidities make it more costly for firms to hire new workers and shift the adjustment from quantities to prices. A higher degree of UR thus increases the volatility of inflation differentials but reduces the volatility of unemployment differentials. Real wage rigidities, which shift the adjustment from labor prices to labor quantities, substantially increase the volatility of unemployment differentials but have little impact on the volatility of inflation differentials. Second, we find that the volatility of both inflation and unemployment differentials increase in the degree of asymmetry of labor market rigidities across countries. The reason is that differences in labor market institutions lead to strong asymmetric responses to common shocks. Finally, we analyze interaction effects between labor market institutions and find that the effects of the two rigidities on inflation and unemployment differentials tend to offset each other if they are positively correlated at the country level, but reinforce each other if they are negatively correlated. Overall, our results suggest that asymmetries in labor market structures worsen the adjustment mechanism of a currency union to symmetric and asymmetric shocks.

A few currency union models have been proposed in recent years (see, among others, Benigno, 2004, Galí and Monacelli, 2008, and Benigno and Lopez-Salido, 2006). The literature has focused on the implications of different degrees of nominal rigidities in member countries. The main result is that, when asymmetries in the degree of price stickiness are present, an inflation targeting strategy that gives higher weight to inflation in the "sticky price" region is nearly optimal (Benigno, 2004). Most of these works assume perfectly competitive labor markets and thus ignore a fundamental source of asymmetry among member countries, namely the wide heterogeneity in European labor market institutions.

Campolmi and Faia (2011) are the first to integrate labor markets frictions "à la MortensenPissarides" into a currency union model. Their paper, which studies the link between inflation volatility and unemployment insurance coverage, represents an important first step towards an understanding of how the transmission mechanism of monetary policy works in the presence of asymmetries in the structure of labor markets. ${ }^{3}$ Our paper differs from their analysis in three important aspects: First, we take a different perspective on labor markets, as we distinguish between the two types of labor market rigidities mentioned above. Second, we focus our analysis on the volatility of differentials, which directly reflect how shocks are absorbed in the currency union, whereas they analyze differences in the volatility of inflation

wage rigidities for business cycle fluctuations in OECD countries.

${ }^{3}$ Other contributions related to our paper, but with a different focus, include Andersen and Seneca (2010), Poilly and Sahuc (2008), Dellas and Tavlas (2005) and Fahr and Smets (2010). 
across member countries. Finally, we also analyze the effect of labor market institutions on the volatility of unemployment differentials. More precisely, we analyze fluctuations of unemployment in deviations from the efficient allocation and thus focus the attention on inefficient allocations in the labor market. This distinction is important because in a currency union that is hit by symmetric and asymmetric shocks, fluctuations in unemployment are not necessarily efficient.

The remainder of the paper is organized as follows. Section 2 describes the model. Section 3 discusses the calibration strategy. Section 4 studies the dynamics of the model under different calibrations. Section 5 concludes.

\section{The Model}

A currency union is a group of regions or countries sharing the same currency, with a single central bank entitled to conduct monetary policy ${ }^{4}$. To keep things simple, we consider a currency union consisting of two regions, Home and Foreign, of the same size (normalized to 1). Each economy, which is populated by identical, infinitively lived households, is specialized in the production of a bundle of differentiated goods. Production of these goods takes place in two sectors. Wholesale firms produce intermediate goods in competitive markets and sell their output to monopolistic retailers. Retailers transform the intermediate goods into final goods and sell them to the households. Price rigidities arise at the retail level, while hiring frictions in the intermediate goods sector. There is no migration across regions. Capital markets are complete. Wages are set in individual bargaining between the employer and the employee. Countries are symmetric for everything apart from labor market institutions ${ }^{5}$.

\footnotetext{
${ }^{4}$ The basic framework of the currency union is inspired by Benigno (2004) and Galí and Monacelli (2008). The structure of the labor market builds on Blanchard and Galí (2010). The complete derivation of the model is described in the Appendix, which is available on the corresponding author's webpage.

${ }^{5}$ We deviate from Campolmi and Faia in two important respects: First, we use Blanchard and Galí's framework instead of a Mortensen-Pissarides type search-matching model. Krause, Lopez-Salido and Lubik (2008b), however, demonstrated that the two models are basically equivalent, and thus all our results would carry over to a search-matching model. Second, Campolmi and Faia's model features endogenous job destruction. As argued further below, we believe that introducing this additional channel of adjustment would not change our results. In fact, in a model with endogenous job destruction, rigidities such as firing costs have the same effects on unemployment and inflation as what we capture with the term unemployment rigidity (UR) in a model without endogenous job destruction. For details, see footnote 15 regarding Zanetti (2010) and Thomas and Zanetti (2009).
} 


\subsection{Assumptions}

\subsubsection{Preferences}

The representative household in country $i(i=H$ or $F)$ maximizes a standard lifetime utility, which depends on the household's consumption and disutility of work:

$$
E_{0} \sum_{t=0}^{\infty} \beta^{t} \Omega_{t}\left\{\frac{C_{t}^{1-\sigma}}{1-\sigma}-\chi \frac{\left(N_{t}^{H}\right)^{1+\phi}}{1+\phi}\right\}, \quad E_{0} \sum_{t=0}^{\infty} \beta^{t} \Omega_{t}^{*}\left\{\frac{C_{t}^{* 1-\sigma}}{1-\sigma}-\chi^{*} \frac{\left(N_{t}^{F}\right)^{1+\phi}}{1+\phi}\right\}
$$

where variables with star refer to the foreign country. $N_{t}^{i}$ denotes the number of employed individuals in the representative household of country $i$ while $\Omega_{t}^{i}$ denotes shocks to the household's discount factor (preference shocks) ${ }^{6} . C_{t}$ and $C_{t}^{*}$ are the composite consumption indexes for the home and foreign country respectively, defined as:

$$
C_{t}=\frac{\left(C_{t}^{H}\right)^{1-\alpha}\left(C_{t}^{F}\right)^{\alpha}}{(1-\alpha)^{1-\alpha} \alpha^{\alpha}}, \quad C_{t}^{*}=\frac{\left(C_{t}^{F, *}\right)^{1-\alpha}\left(C_{t}^{H, *}\right)^{\alpha}}{(1-\alpha)^{1-\alpha} \alpha^{\alpha}}
$$

where $C_{t}^{H}$ is the quantity of the good produced at Home and consumed by home residents, while $C_{t}^{H, *}$ denotes the quantity of the good produced at Home and consumed by foreign residents. These consumption bundles are given by the usual CES aggregator with elasticity of substitution between varieties $\epsilon . \alpha \in[0,1]$ is the weight on the imported goods in the utility of private consumption.

Utility maximization for the home household is subject to a sequence of budget constraints which, conditional on optimal allocation of expenditures across varieties, is given by $^{7}$ :

$$
P_{t} C_{t}+E_{t}\left\{Q_{t, t+1} V_{t+1}^{H}\right\} \leq V_{t}^{H}+W_{t}^{H} N_{t}^{H}+\Pi_{t}^{H}
$$

where $P_{t}=\left(P_{t}^{H}\right)^{1-\alpha}\left(P_{t}^{F}\right)^{\alpha}$ is the home CPI index, $V_{t}^{H}$ is the nominal payoff in period $t$ of the portfolio held at the end of period $t-1$ and $Q_{t, t+1}$ is the stochastic discount factor for one-period ahead nominal payoffs, which is common across countries. $W_{t}^{H}$ is the nominal wage and $\Pi_{t}^{H}$ denotes the profits received by the home households, net of lump-sum taxes. $P_{t}^{H}$ and $P_{t}^{F}$ are the Dixit-Stiglitz domestic price indexes of the home and foreign countries.

\footnotetext{
${ }^{6}$ We model the preference shock as in Smets and Wouters (2003).

${ }^{7}$ Implicit in the budget constraint is the assumption that the law of one price holds across the union.
} 


\subsubsection{The Terms of Trade and the Real Exchange Rate}

We define the bilateral terms of trade between the home and foreign country as the ratio of the price of goods produced in country $\mathrm{F}$ over the price of goods produced in country $\mathrm{H}$ :

$$
S_{t}=\frac{P_{t}^{F}}{P_{t}^{H}}
$$

As the law of one price holds for all goods, which implies $P_{t}^{F}=P_{t}^{F, *}$ and $P_{t}^{H}=P_{t}^{H, *}$, the $\mathrm{CPI}$ and the domestic price indexes in the two regions are related according to:

$$
P_{t}=P_{t}^{H}\left(S_{t}\right)^{\alpha}, \quad P_{t}^{*}=P_{t}^{F}\left(S_{t}\right)^{-\alpha}
$$

The real exchange rate $R E R_{t}$ is defined as the ratio between foreign and home CPIs and is related to the terms of trade according to:

$$
R E R_{t}=\frac{P_{t}^{*}}{P_{t}}=\left(S_{t}\right)^{1-2 \alpha}
$$

\subsubsection{Technology}

In each country there are two sectors of production: a retail sector and a wholesale sector. The retail sector is composed by a continuum of monopolistic retailers indexed by $z \in[0,1]$, each producing one differentiated consumption good. All retailers share the same technology, which transforms one unit of intermediate goods into one unit of retail goods:

$$
Y_{t}^{i}(z)=X_{t}^{i}(z)
$$

where $X_{t}^{i}(z)$ is the quantity of the intermediate good bought by retailer $z$ in country $i$.

The intermediate good is produced by a large number of perfectly competitive firms, indexed by $j \in[0,1]$, using labor as the only input:

$$
X_{t}^{i}(j)=A_{t}^{i} N_{t}^{i}(j)
$$

where the variables $A_{t}^{i}$ represent the state of technology in country $i$.

In each period a fraction $\delta^{i}$ of the employed lose their job and join the unemployment pool. Employment in firm $j$ evolves according to:

$$
N_{t}^{i}(j)=\left(1-\delta^{i}\right) N_{t-1}^{i}(j)+h_{t}^{i}(j)
$$


where $h_{t}^{i}(j)$ is the number of new hires for firm $j$ in country $i$.

\subsubsection{Labor Market Flows and Hiring Costs}

We assume all unemployed in the family look for a job. Aggregate hiring in country $i$, $h_{t}^{i} \equiv \int_{0}^{1} h_{t}^{i}(j) d j$, evolves according to:

$$
h_{t}^{i}=N_{t}^{i}-\left(1-\delta^{i}\right) N_{t-1}^{i}
$$

where $N_{t}^{i} \equiv \int_{0}^{1} N_{t}^{i}(j) d j$ denotes aggregate employment. The number of searching workers who are available for hire, $U_{t}^{i}$, is defined as

$$
U_{t}^{i}=1-\left(1-\delta^{i}\right) N_{t-1}^{i}
$$

and we define unemployment in our model as the fraction of the population who are left without a job after hiring takes place, $u_{t}^{i}=1-N_{t}^{i}$.

Labor market frictions are introduced by assuming that hiring labor is costly. Following Blanchard and Galí (2010), we define the labor market tightness index as the ratio of aggregate hires to the number of searching individuals, $x_{t}^{i} \equiv \frac{h_{t}^{i}}{U_{t}^{i}}$, and we assume that unit recruitment costs are an increasing function of the labor market tightness index:

$$
G_{t}^{i}=A_{t}^{i} B^{i}\left(x_{t}^{i}\right)^{\varphi}
$$

where $\varphi>0$ and $B^{i}$ is a positive constant. Note that from the viewpoint of the unemployed $x_{t}^{i}$ can be interpreted as the probability of finding a new job.

\subsection{Equilibrium under Flexible Prices}

\subsubsection{Price Setting}

The intermediate good produced at Home is sold to home retailers at relative price $\mu_{t}^{H}=\frac{P_{I, t}}{P_{t}^{H}}$, with $P_{I, t}$ being the nominal price of the intermediate good. The problem of the wholesale firm is to maximize profits by choosing optimally the number of workers it would like to hire in each period. Profit maximization gives the first order condition:

$$
\mu_{t}^{H} A_{t}^{H}=w_{t}^{H, R}\left(S_{t}\right)^{\alpha}+G_{t}^{H}-\left(1-\delta^{H}\right) E_{t}\left\{\beta_{t, t+1} G_{t+1}^{H}\right\}
$$

where $w_{t}^{H, R}=\frac{W_{t}^{H}}{P_{t}}$ is the real wage expressed in terms of the consumption good and where $\beta_{t, t+1}=\beta \frac{\Omega_{t+1}}{\Omega_{t}}\left(\frac{C_{t+1}}{C_{t}}\right)^{-\sigma}\left(\frac{S_{t}}{S_{t+1}}\right)^{\alpha}$. Equation (4) states that the real marginal revenue product 
of labor (the left-hand side) has to equal its real marginal cost, that now includes not only real wages but also a component associated with hiring costs. This new component is composed of two terms. The first, $G_{t}^{H}$, represents the additional cost the firm faces to hire a new worker; the second - the last term in (4) - reflects the savings in future hiring costs resulting from increasing the number of employees today.

Under flexible prices, the optimal price setting rule of final goods firms takes the form of a mark-up over the real marginal costs:

$$
\frac{P_{t}^{H}(z)}{P_{t}^{H}}=\frac{\epsilon}{\epsilon-1} \mu_{t}^{H}
$$

and thus in a symmetric equilibrium, where $P_{t}^{H}(z)=P_{t}^{H}$ for all $z \in[0,1]$, the optimal price setting implies $\mu_{t}^{H}=\frac{\epsilon-1}{\epsilon}$ for all $t$. It follows that under flexible prices:

$$
w_{t}^{H, R}\left(S_{t}\right)^{\alpha}=A_{t}^{H} \mu^{H}-G_{t}^{H}+\left(1-\delta^{H}\right) E_{t}\left\{\beta_{t, t+1} G_{t+1}^{H}\right\}
$$

where $\mu^{H}$ is the inverse of the mark-up. A similar condition hold for the foreign country.

\subsubsection{Wage Determination}

We introduce real wage rigidity by employing a version of Hall's (2005) notion of wage norm. A wage norm may arise as a result of social conventions that constrain wage adjustment. One way to model this is to assume that the real wage $w_{t}^{H, R}$ is a weighted average of the Nash bargained wage $w_{t}^{H, N a s h}$ and a wage norm $w^{H}$, which is assumed to be the wage prevailing in steady state. Specifically:

$$
w_{t}^{H, R}=\left(w_{t}^{H, N a s h}\right)^{1-\gamma}\left(w^{H}\right)^{\gamma}, \quad w_{t}^{F, R}=\left(w_{t}^{F, N a s h}\right)^{1-\gamma^{*}}\left(w^{F}\right)^{\gamma^{*}}
$$

where $\gamma$ and $\gamma^{*}$ are indexes of the real wage rigidities present in the home and foreign economy, with $\gamma \in[0,1]$ and $\gamma^{*} \in[0,1]$. One can show that the Nash bargained wage is determined as:

$$
w_{t}^{H, N a s h}\left(S_{t}\right)^{\alpha}=m r s_{t}+\eta\left\{G_{t}^{H}-\left(1-\delta^{H}\right) E_{t}\left\{\beta_{t, t+1}\left[\left(1-x_{t+1}^{H}\right) G_{t+1}^{H}\right]\right\}\right\}
$$


where $\eta$ is the relative weight of workers in the Nash bargaining and $m r s_{t}=\chi C_{t}^{\sigma}\left(N_{t}^{H}\right)^{\phi}\left(S_{t}\right)^{\alpha}$ denotes the marginal rate of substitution between consumption and leisure ${ }^{8}$. The Nash wage rule (7) together with equations (6) and (5) determines the evolution of unemployment under flexible prices. Similar conditions hold for the foreign country.

\subsubsection{International Risk Sharing and Market Clearing}

Households have access to a complete set of contingent claims, traded internationally. Combining the first order conditions for state contingent securities in the two countries, we get:

$$
S_{t}^{1-2 \alpha}=\psi \frac{u^{\prime}\left(C_{t}^{*}\right)}{u^{\prime}\left(C_{t}\right)}
$$

where $\psi$ is a constant, reflecting initial conditions regarding relative net asset positions. To keep things simple, we assume $\psi=1$. Throughout our analysis we assume home bias in consumption, i.e. $\alpha<1 / 2$, and thus movements in the terms of trade are reflected in different consumption rates.

The clearing of all markets implies, for the home and foreign country respectively,

$$
Y_{t}-G_{t}^{H} h_{t}^{H}=\varpi_{t} C_{t} D_{t}^{H} \quad ; \quad Y_{t}^{*}-G_{t}^{F} h_{t}^{F}=\varpi_{t}^{*} C_{t}^{*} D_{t}^{F}
$$

where $D_{t}^{H} \equiv \int_{0}^{1}\left(\frac{P_{t}^{H}(z)}{P_{t}^{H}}\right)^{-\epsilon} d z$ and $D_{t}^{F} \equiv \int_{0}^{1}\left(\frac{P_{t}^{F}(z)}{P_{t}^{F}}\right)^{-\epsilon} d z$ are measures of price distortions and $\varpi_{t}$ and $\varpi_{t}^{*}$ capture the expenditure switching effect of terms of trade fluctuations. ${ }^{9}$

\subsubsection{The Efficient Equilibrium}

In a currency union with asymmetric shocks, not all fluctuations in economic activity are inefficient. In order to determine the inefficient portion of unemployment and output fluctuations, this section briefly characterizes the conditions under which the decentralized allo-

${ }^{8}$ We follow Blanchard and Galí (2010) and abstract from unemployment benefits. Introducing unemployment benefits in our model, the wage rule would become:

$$
w_{t}^{H, N a s h}\left(S_{t}\right)^{\alpha}=m r s_{t}+b_{t}+\eta\left\{G_{t}^{H}-\left(1-\delta^{H}\right) E_{t}\left\{\beta_{t, t+1}\left[\left(1-x_{t+1}^{H}\right) G_{t+1}^{H}\right]\right\}\right\}
$$

where $b_{t}$ is the unemployment benefit (expressed in domestic prices). Campolmi and Faia (2011) extensively study the effect of differences in $b_{t}$ on inflation differentials inside a currency union. They find that countries with higher replacement rates tend to have a lower volatility of inflation and marginal costs. Unemployment benefits mainly limit wage variations and thus have the opposite effect of UR in our model.

$$
\begin{aligned}
& { }^{9} \text { Specifically, } \varpi_{t}=S_{t}^{\alpha}\left[(1-\alpha)+\alpha S_{t}^{\varrho}\left(\frac{\Omega_{t}}{\Omega_{t}^{*}}\right)^{-\frac{1}{\sigma}}\right] \text { and } \varpi_{t}^{*}=\left(S_{t}\right)^{-\alpha}\left[\alpha\left(S_{t}\right)^{-\varrho}\left(\frac{\Omega_{t}}{\Omega_{t}^{*}}\right)^{\frac{1}{\sigma}}+(1-\alpha)\right] \text {, where } \\
& \varrho=\left(1-\frac{1}{\sigma}\right)(1-2 \alpha) .
\end{aligned}
$$


cation is efficient. The constrained efficient allocation is found by assuming that the social planner maximizes the welfare of the union, taking as given the technological constraints and the hiring frictions that are present in the decentralized economy (see the Appendix for details). Comparing the solution of the social planner's problem with the decentralized equilibrium under flexible prices leads to the following result.

Proposition 1 Under flexible prices, the decentralized equilibrium corresponds to the constrained efficient equilibrium if three conditions are satisfied: 1. Monopolistic distortions in the final goods market are eliminated through a production subsidy; 2. The Hosios condition holds, i.e. $\varphi=\eta$; 3. Real wages are fully flexible, i.e. $\gamma^{i}=0$ for $i=H, F$.

Proof. See the Appendix.

Proposition 1 highlights the distortions that characterize the real side of the economy: monopolistic distortions in the goods market, search externalities in the labor market, and real wage rigidities. In the following we assume, as it is common practice ${ }^{10}$, that the first two conditions are met, so that the steady state of the decentralized allocation corresponds to the efficient one, and focus on real wage rigidities as the main source of deviation of the flexible price allocation from the efficient allocation.

\subsection{Equilibrium under Sticky Prices}

We introduce nominal price rigidity into retailers' maximization problem using the formalism à la Calvo (1983), where each period firms may reset their prices with a probability $1-\theta$. Thus we obtain the New Keynesian Phillips curve, which is written in log-linear form as:

$$
\hat{\pi}_{t}^{H}=\beta E_{t} \hat{\pi}_{t+1}^{H}+\lambda_{p} \widehat{m c}_{t}^{H}
$$

where $\hat{\pi}_{t}^{H}$ is domestic (i.e. producer prices') inflation, $\widehat{m c}_{t}^{H}=\hat{\mu}_{t}^{H}$ represents the log deviation of real marginal costs from its steady state value and $\lambda_{p}=(1-\beta \theta)(1-\theta) / \theta$. Note that while (10) looks like the standard New Keynesian Phillips curve, the dynamics of the real marginal costs are now substantially different, as they are deeply affected by the labor market institutions. In fact, log-linearizing equation (4) we can rewrite marginal costs as:

$$
\widehat{m c}_{t}^{H}=\frac{w(S)^{\alpha}}{\mu}\left(\hat{w}_{t}^{H, R}+\alpha \hat{s}_{t}-\hat{a}_{t}^{H}\right)+\frac{g \varphi}{\mu} \hat{x}_{t}^{H}-\beta\left(1-\delta^{H}\right) \frac{g}{\mu} E_{t}\left\{\hat{\beta}_{t, t+1}+\Delta a_{t+1}^{H}+\varphi \hat{x}_{t+1}^{H}\right\}
$$

\footnotetext{
${ }^{10}$ See, e.g., Blanchard and Galí (2010), Ravenna and Walsh (2010) and Thomas (2008).
} 
where variables with hat denote log-deviations from steady state, variables without subscript steady state values, $\mu$ is equal to the inverse of the mark-up of retailers and $g$ is the steady state value of unit hiring costs $G_{t}^{H}$. Marginal costs depend not only on the evolution of real wages, terms of trade and productivity, as in the standard New Keynesian model; they also depend on current labor market conditions $\left(x_{t}^{H}\right)$ and on the future labor market conditions, as captured by the last term on the right-hand side. ${ }^{11}$

\subsubsection{Log-linearized Equilibrium Dynamics}

Before characterizing the equilibrium dynamics, let us define $\hat{X}_{t}$ as the deviation of a variable $X_{t}$ around its steady state value. Let us also define $\bar{X}_{t}$ as the (stochastic) efficient equilibrium level of $\hat{X}_{t}$ and $\tilde{X}_{t} \equiv \hat{X}_{t}-\bar{X}_{t}$ as the efficiency gap, i.e. the gap between the actual level $\hat{X}_{t}$ and its efficient counterpart. Finally, we define union-wide variables as $\hat{X}_{t}^{U} \equiv \frac{\hat{X}_{t}^{H}+\hat{X}_{t}^{F}}{2}$.

Our currency union model is quite rich, but still tractable, as it can be characterized in few equations. The demand side of the model is standard. The evolution of the aggregate consumption gap at the union level is captured by the union-wide IS equation:

$$
\tilde{c}_{t}^{U}=E_{t} \tilde{c}_{t+1}^{U}-\frac{1}{\sigma}\left(\hat{\imath}_{t}-E_{t} \hat{\pi}_{t+1}^{U}-\bar{r}_{t}\right)
$$

where $\hat{\pi}_{t}^{U}$ is union-wide inflation, $\bar{r}_{t}=\sigma\left(E_{t} \bar{c}_{t+1}^{U}-\bar{c}_{t}^{U}\right)+\left(1-\rho_{F}\right) \hat{\Omega}_{t}^{U}$ is the natural real interest rate and $\hat{\imath}_{t}$ the common nominal interest rate. Note that the preference shock leads to higher current consumption relative to future consumption, as it makes individuals discount the future more heavily. While the real interest rate affects aggregate consumption, terms of trade movements distribute consumption among the two countries:

$$
\tilde{c}_{t}-\tilde{c}_{t}^{*}=\frac{(1-2 \alpha)}{\sigma} \tilde{s}_{t}
$$

Using the approximation $\tilde{n}_{t}^{i}=-\frac{\tilde{u}_{t}^{i}}{\left(1-u^{i}\right)}$, the market clearing conditions can be expressed as:

$$
\begin{aligned}
& \tilde{c}_{t}=-\tau_{0} \tilde{u}_{t}^{H}-\tau_{1} \tilde{u}_{t-1}^{H}-\left(\alpha+\zeta_{s}\right) \tilde{s}_{t} \\
& \tilde{c}_{t}^{*}=-\tau_{0}^{F} \tilde{u}_{t}^{F}-\tau_{1}^{F} \tilde{u}_{t-1}^{F}+\left(\alpha+\zeta_{s}^{*}\right) \tilde{s}_{t}
\end{aligned}
$$

${ }^{11}$ Under the baseline calibration, the actual values of the marginal costs are:

$$
\widehat{m c}_{t}^{H}=.988\left(\hat{w}_{t}^{H, R}+\alpha \hat{s}_{t}-\hat{a}_{t}^{H}\right)+.324\left\{\hat{x}_{t}^{H}-.960 E_{t}\left(\hat{\beta}_{t, t+1}+\Delta a_{t+1}^{H}+\hat{x}_{t+1}^{H}\right)\right\}
$$

It can be shown that the weight on current and future labor market conditions (the term in curled brackets) lies in between the values of Blanchard and Galí (2010) and Krause, Lopez-Salido and Lubik (2008a,b). 
where $\tau_{0}^{i}=\frac{1-g^{i}\left(1+\varphi^{i}\right)}{N^{i}\left(1-\delta^{i} g^{i}\right)}, \tau_{1}^{i}=\frac{g^{i}\left(1-\delta^{i}\right)\left(1+\varphi^{i}(1-x)\right)}{N^{i}\left(1-\delta^{i} g^{i}\right)}$ and where the parameters $\zeta_{s}^{i}$ are zero for $\sigma=1$ and positive but small for $\sigma>1 .{ }^{12}$ Note that movements in the terms of trade lead to changes in consumption at Home and Foreign, and this effect is larger the smaller the degree of home bias in consumption (i.e. the larger is $\alpha$ ).

The aggregate supply equations for Home and Foreign are:

$$
\begin{aligned}
\hat{\pi}_{t}^{H} & =\beta E_{t} \hat{\pi}_{t+1}^{H}-h_{0} \tilde{u}_{t}^{H}+h_{L} \tilde{u}_{t-1}^{H}+h_{F} E_{t} \tilde{u}_{t+1}^{H}+h_{F S} E_{t} \tilde{s}_{t+1}+h_{0 S} \tilde{s}_{t}-\gamma h_{T} \hat{T}_{t}^{H} \\
\hat{\pi}_{t}^{F} & =\beta E_{t} \hat{\pi}_{t+1}^{F}-h_{0}^{*} \tilde{u}_{t}^{F}+h_{L}^{*} \tilde{u}_{t-1}^{F}+h_{F}^{*} E_{t} \tilde{u}_{t+1}^{F}-h_{F S}^{*} E_{t} \tilde{s}_{t+1}-h_{0 S}^{*} \tilde{s}_{t}-\gamma^{*} h_{T}^{*} \hat{T}_{t}^{F}
\end{aligned}
$$

where the coefficients $h$ are functions of the structural parameters characterizing the two economies ${ }^{13}$, and the term $\hat{T}_{t}^{i}$ introduces an endogenous trade-off of monetary policy between inflation stabilization and unemployment gap stabilization. This trade-off is generated by the presence of real wage rigidities which make the response of real wages dynamically inefficient (see, e.g., Blanchard and Galí, 2010) and follows:

$$
\hat{T}_{t}^{H}=-\kappa_{0} \bar{u}_{t}^{H}+\kappa_{L} \bar{u}_{t-1}^{H}+\kappa_{F} \bar{u}_{t+1}^{H}+\kappa_{S F} \bar{s}_{t+1}-\kappa_{S} \bar{s}_{t}+\kappa_{D} \hat{\Omega}_{t}-\kappa_{D^{*}} \hat{\Omega}_{t}^{*}+\kappa_{A} \hat{a}_{t}^{H}
$$

A similar condition holds for the foreign country. With completely flexible real wages (i.e. $\gamma=0$ ), wages and marginal costs move in proportion to a distributed lag of employment and terms of trade gaps, and productivity shocks do not enter as a separate term in the Phillips curve. On the contrary, in the presence of real wage rigidities (i.e. $\gamma>0$ ), productivity shocks enter as a negative cost push shock because wages do not move enough to absorb the impact of the shock, and this translates into inefficient allocations in the product and labor markets. Preference shocks also enter as a cost push shock, mainly because they affect how firms and workers discount the future value of an employment relationship, but these effects can be shown to be quantitatively small.

Note also that the Phillips Curves depend positively on the current and future evolution of the terms of trade, because the terms of trade not only distribute production among member states, but also affect the wage schedule and the firms' marginal costs (see equations 7 and 11).

From the definition of the terms of trade $S_{t}=\frac{P_{t}^{F}}{P_{t}^{H}}$ we get:

$$
\hat{s}_{t}-\hat{s}_{t-1}=\hat{\pi}_{t}^{F}-\hat{\pi}_{t}^{H}
$$

Finally, we assume that the central bank sets the nominal interest rate by reacting to

\footnotetext{
${ }^{12}$ Specifically, $\zeta_{s}=\frac{\alpha S^{\varrho}}{\alpha S^{\varrho}+(1-\alpha)} \varrho$ and $\zeta_{s}^{*}=\frac{\alpha S^{-\varrho}}{\alpha S^{-\varrho}+(1-\alpha)} \varrho$, with $\varrho=\left(1-\frac{1}{\sigma}\right)(1-2 \alpha)$.

${ }^{13}$ The expression for the parameters is given in the Appendix.
} 
union inflation $\hat{\pi}_{t}^{U}$ and the output gap $\tilde{y}_{t}^{U}$, according to the following monetary policy rule:

$$
\hat{\imath}_{t}=\omega_{R} \hat{\imath}_{t-1}+\left(1-\omega_{R}\right)\left(\omega_{\pi} \hat{\pi}_{t}^{U}+\omega_{y} \tilde{y}_{t}^{U}\right)+\varepsilon_{t}
$$

where $\omega_{R}$ captures the degree of interest rate smoothing and $\varepsilon_{t}^{m}$ is a monetary policy shock. Equations (12)-(19), together with the evolution of the variables under the efficient allocation, characterize our equilibrium dynamics.

\section{Calibration}

In our baseline calibration, we assume that Home and Foreign are perfectly symmetric. The parameters are consistent with those standard in the New Keynesian literature.

\begin{tabular}{|c|c|c|}
\hline \multirow{2}{*}{$\begin{array}{l}\text { Parameter } \\
\text { Preferences }\end{array}$} & \multicolumn{2}{|l|}{ Value } \\
\hline & & \\
\hline Discount rate $\beta$ & 0.992 & Annual real interest rate of $3.3 \%$ \\
\hline Elasticity of int. substitution $\sigma$ & 1 & Log utility \\
\hline Labor supply elasticity $\phi^{i}$ & 0 & Homogeneous tastes for leisure \\
\hline Share of imported goods $\alpha$ & 0.25 & Campolmi and Faia (2011) \\
\hline \multicolumn{3}{|l|}{ Labor market } \\
\hline Job finding rate $x^{i}$ & 0.45 & Monthly rate of 0.18 \\
\hline Job separation rate $\delta^{i}$ & 0.071 & Reconciles $u^{i}=8 \%$ and $x^{i}=0.45$ \\
\hline Aggregate hiring costs $g h$ & $0.01 Y$ & Walsh (2005), Blanchard and Galí (2010) \\
\hline Elasticity of hiring cost function, $\varphi^{i}$ & 1 & Blanchard and Galí (2010) \\
\hline Relative bargaining power $\eta^{i}$ & 1 & Blanchard and Galí (2010) \\
\hline \multicolumn{3}{|l|}{ Price and wage rigidities } \\
\hline Price rigidity, $\theta$ & 0.66 & Average price duration of 3 quarters \\
\hline Real wage rigidity $\gamma^{i}$ & 0.5 & Blanchard and Galí (2010) \\
\hline \multicolumn{3}{|l|}{ Monetary policy } \\
\hline Response to inflation $\omega_{\pi}$ & 1.5 & Christoffel, Kuester and Linzert (2009) \\
\hline Output gap $\omega_{y}$ & $\frac{0.5}{4}$ & Christoffel, Kuester and Linzert (2009) \\
\hline Interest rate smoothing $\omega_{R}$ & 0.85 & Christoffel, Kuester and Linzert (2009) \\
\hline \multicolumn{3}{|l|}{ Shocks } \\
\hline Std. deviation interest rate shock $\sigma_{\epsilon}$ & $0.1 \%$ & Thomas and Zanetti (2009) \\
\hline Autocorr. productivity shocks $\rho_{a}^{i}$ & 0.95 & Sahuc and Smets (2008) \\
\hline Corr. productivity shocks $\rho_{\sigma_{a}}$ & 0.258 & Backus et al. (1992) \\
\hline Std. deviation productivity shock $\sigma_{a}^{i}$ & $0.624 \%$ & Smets and Wouters (2003) \\
\hline Autocorr. preference shocks $\rho_{\Omega}^{i}$ & 0.85 & Smets and Wouters (2003) \\
\hline Corr. preference shocks $\rho_{\sigma_{\Omega}}$ & 0.258 & Same as corr. productivity shock \\
\hline Std. deviation preference shocks $\sigma_{\Omega}^{i}$ & $0.392 \%$ & Smets and Wouters (2003) \\
\hline
\end{tabular}

Table 1: Baseline calibration 
Preferences: Time is taken as quarters. The discount factor $\beta$ is set to 0.992 , which implies a riskless annual return of about 3.3 percent. In the baseline calibration, the utility is $\log$ in consumption $(\sigma=1)$. We assume the labor supply elasticity to be $\phi^{i}=0$. This is consistent with our model if the members of the household have homogenous tastes for leisure. The home bias parameter $\alpha$, representing the share of imported goods on total consumption, is set to 0.25 .

Technology: Following Blanchard and Galí (2010) we set the parameter $\varphi^{i}$ in the hiring cost function, representing the sensitivity of hiring costs to labor market conditions, to be $\varphi^{i}=1$. The steady state level of productivity $A^{i}$ is normalized to 1 .

The degree of price rigidity $\theta^{i}$ is set equal to 0.66 , consistent with data on price duration. Following Campolmi and Faia (2011) and Blanchard and Galí (2010), we set the degree of real wage rigidity $\gamma^{i}$ equal to 0.5 .

Shocks: The standard deviation of the productivity shock, and the persistence and standard deviation of preference shocks are respectively $\sigma_{a}^{i}=0.00624, \rho_{\Omega}=0.85$ and $\sigma_{\Omega}^{i}=0.00392$, as in the estimates of Smets and Wouters (2003) for the Euro Area. The persistence of the productivity shock is set to the standard value of $\rho_{a}=0.95$, which is also consistent with the estimates of Sahuc and Smets (2008). Following Backus, Kehoe and Kydland (1992) we set the correlation between the productivity shocks $\rho_{\sigma_{a}}$ to 0.258 . Since we do not have data on the correlation of preference shocks across countries, in the baseline calibration we use the same value as for productivity shocks.

For the monetary policy we use a simple rule reacting to inflation with an elasticity $\omega_{\pi}$ of 1.5 , to the output gap with an elasticity $\omega_{y}$ of $\frac{0.5}{4}$ and a persistence in interest rates $\omega_{R}=0.85 .{ }^{14}$ The standard deviation of monetary policy shocks is set to 0.001 , consistent with the estimates by Thomas and Zanetti (2009).

The labor market: In the baseline calibration, we set unemployment in country $i$ to be $u^{i}=0.08$, which matches roughly the average unemployment rate in Europe. The job-finding rate $x^{i}$ is set to 0.45 , which corresponds to a monthly rate of 0.18 . Given $u^{i}$ and $x^{i}$, it is possible to determine the separation rate using the relation $\delta^{i}=u^{i} x^{i} /\left(\left(1-u^{i}\right)\left(1-x^{i}\right)\right)$. We obtain a value $\delta^{i}=0.071$. The relative bargaining power $\eta^{i}$ is set to 1 , which implies that firms and workers have the same bargaining power. The scaling parameter $B^{i}$ is chosen such that hiring costs represent a 1 percent fraction of steady state output, as in Walsh (2005). The parameters $\chi^{i}$ can then be determined using steady state identities.

In our analysis in the next section, we distinguish between two types of labor market imperfections: Unemployment Rigidities (UR), which capture the institutions - such as em-

\footnotetext{
${ }^{14}$ As in Christoffel, Kuester and Linzert (2009), we divide the weight on the output gap $\omega_{y}$ by 4 because we do not annualize the interest rate.
} 
ployment protection legislation, hiring costs and the matching technology - that limit the flows in and out of unemployment; and Real Wage Rigidities ( $R W R$ ), intended to capture all the institutions - including wage norms, wage indexation and the wage bargaining mechanism and legislation - which influence the responsiveness of real wages to economic activity.

To study the role of different degrees of RWR, we simulate the model varying $\gamma^{i}$ from 0.25 to 0.75 . Calibrating the degree of UR is a more challenging task, as the overall degree of "rigidity" in the labor market does not depend only on one parameter but on the entire configuration of the labor market. Following Blanchard and Galí (2010), we define a labor market as "flexible" when the job-finding and the separation rate are high; the opposite holds in a "sclerotic" labor market. The following tabulation shows the parameters implied by our calibration strategy:

\begin{tabular}{|l|c|c|}
\hline & Index of Rigidity $=0$ & Index of Rigidity $=1$ \\
\hline UR & $x^{i}=0.7 / \delta^{i}=0.12 / u^{i}=0.05$ & $x^{i}=0.2 / \delta^{i}=0.03 / u^{i}=0.11$ \\
\hline RWR & $\gamma^{i}=0.25$ & $\gamma^{i}=0.75$ \\
\hline
\end{tabular}

As our UR index increases from 0 to 1 , the job-finding rate decreases from 0.7 to 0.2 , the separation rate decreases from 0.12 to 0.03 and the unemployment rate increases from 0.05 to 0.11. Note that we keep constant total hiring costs in steady state as percentage of GDP. This implies that marginal hiring costs are higher in labor markets with low hiring rates (i.e. high UR). This is consistent with a view of "sclerotic" economies characterized by institutional constraints on the hiring process. ${ }^{15}$ Note also that our baseline calibration refers to an economy with $U R=0.5$ and $R W R=0.5$.

Simulations of the model under the baseline calibration show that the volatilities of the model are close to the data. The standard deviation of output, inflation and unemployment of the Euro Area are 0.85, 0.5 and 4.59, compared to 0.83, 0.43 and 4.63 in our model ${ }^{16}$.

\footnotetext{
${ }^{15}$ Zanetti (2010) and Thomas and Zanetti (2009) introduce firing costs in a closed economy search and matching model and find that firing costs increase inflation volatility but reduce output volatility. In a reduced form but intuitive way, our calibration of unemployment rigidities also captures these firing costs: we find that increasing unemployment rigidities has the same effects on inflation and output volatilities as firing costs in Zanetti (2010) and Thomas and Zanetti (2009).

${ }^{16}$ The standard deviations of actual Euro Area data are taken from Christoffel, Kuester and Linzert (2009), who use quarterly data for the Euro Area from 1984Q1 to 2006Q4. Both data and model are detrended with an HP filter $(\lambda=1600)$. In order to facilitate the comparison, inflation is computed in a year to year base $\left(\hat{\pi}_{t}^{y o y}=\log P_{t}-\log P_{t-4}\right)$ and the volatility of unemployment is calculated in percentage terms.
} 


\section{The Dynamics of the Currency Union}

In this section we study how different labor market structures are likely to affect the functioning of a currency union. The main focus is on the evolution of inflation and unemployment differentials because they directly reflect how shocks are absorbed in the monetary area. Labor market rigidities can affect these differentials in two main ways. First, the presence of labor market rigidities may affect the size and persistence of unemployment and inflation differentials following asymmetric shocks. Second, symmetric shocks may have asymmetric effects when the two regions have different labor market structures. How do these effects operate? Are they likely to be important or negligible? To answer these questions, we simulate the dynamic behavior of the model in response to three types of shocks: productivity shocks (symmetric and asymmetric), preference shocks (symmetric and asymmetric) and monetary policy shocks.

\subsection{Labor Market Rigidities and the Phillips Curve}

To gain some intuition on how labor market structures influence the adjustment mechanism of member countries to shocks, it is helpful to look at the Phillips curve, which we rewrite here for convenience:

$$
\hat{\pi}_{t}^{H}=\beta E_{t} \hat{\pi}_{t+1}^{H}-h_{0} \tilde{u}_{t}^{H}+h_{L} \tilde{u}_{t-1}^{H}+h_{F} E_{t} \tilde{u}_{t+1}^{H}+h_{F S} E_{t} \tilde{s}_{t+1}+h_{0 S} \tilde{s}_{t}-\gamma h_{T} \hat{T}_{t}^{H}
$$

Labor market rigidities affect the supply side of member countries through their impact on the parameters $h$. We concentrate our attention on the two key parameters:

- The "slope coefficient" $h_{0}$, which captures the elasticity of inflation to unemployment changes. $^{17}$

- The "trade-off coefficient" $\gamma h_{T}$, which determines to what extent productivity and preference shocks enter as cost push shocks in the Phillips curve (through $\hat{T}_{t}^{H}$ ).

Figure 1 shows how the slope coefficient changes for varying degrees of UR and RWR. A higher degree of unemployment rigidity has a strong, positive and non-linear effect on the slope of the Phillips Curve. The reason is that with lower job-finding rates and separations employment adjusts less easily to changing labor market conditions. This in turn implies that marginal costs and hence inflation become more sensitive to unemployment changes. Real

\footnotetext{
${ }^{17}$ In our calibrations, the parameters on lagged $\left(h_{L}\right)$ and future unemployment $\left(h_{F}\right)$ are small relative to $h_{0}$. Therefore, we follow Ravenna and Walsh (2008) and refer to $h_{0}$ as the slope of the Phillips curve. While this is an approximation, we believe it to be useful to develop intuition that will hold throughout the paper.
} 

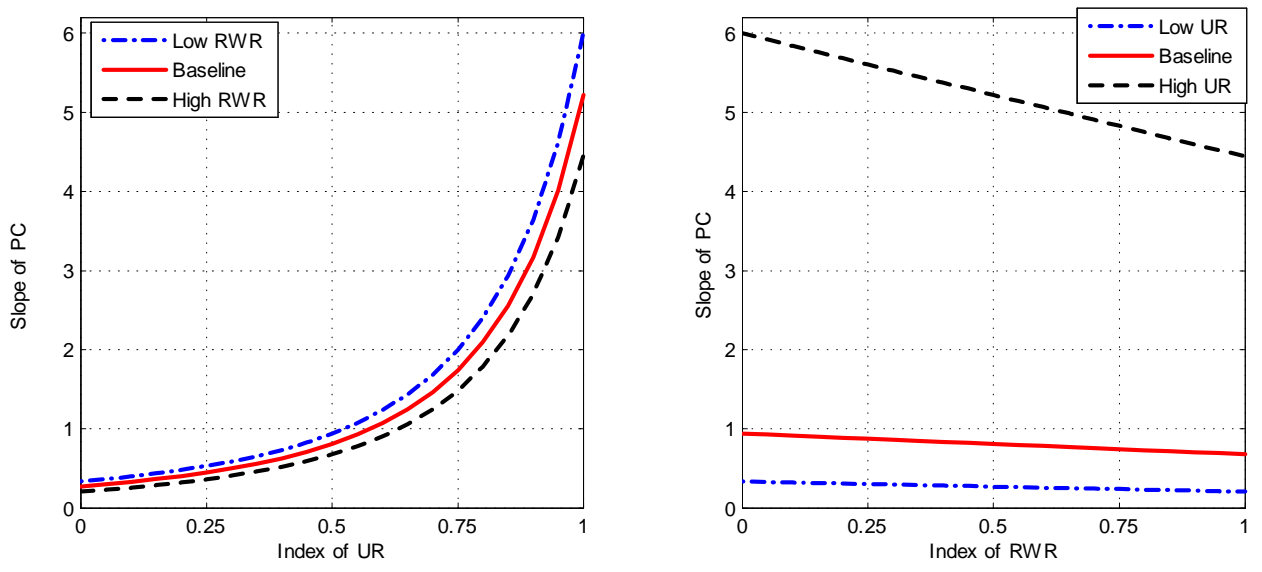

Figure 1: Labor Market Rigidities and the Slope of the Phillips Curve

wage rigidities have the opposite effect on $h_{0}$ : higher degrees of RWR lower the sensitivity of real wages and inflation to unemployment changes. Note also that the sensitivity of the slope to RWR is much smaller than to UR, and becomes sizeable only when UR are high. This suggests that there may be important interaction effects between different types of labor market rigidities.

While UR have a dominant role in explaining the size of the slope coefficient $h_{0}$, RWR are the main determinant of the trade-off coefficient $\gamma h_{T}^{18}$. In particular, note that when $\gamma \neq 0$, preference and productivity shocks alter the endogenous wedge $\hat{T}_{t}^{H}$ and thus enter as cost push shocks in the Phillips curve.

\subsection{Labor Market Rigidities and Inflation and Unemployment Dif- ferentials}

To assess how the dynamics of the currency union depend on the underlying labor market structure, we simulate the economy for different degrees of UR and RWR. Specifically, in this first exercise we change either the degree of UR or the degree of RWR for both countries at the same time. This allows us to understand how the average degree of labor market rigidity in the monetary union affects inflation and unemployment differentials. We define the inflation differential as $\hat{\pi}_{t}^{D}=\hat{\pi}_{t}^{H}-\hat{\pi}_{t}^{F}$ and the unemployment differential as $\tilde{u}_{t}^{D}=\tilde{u}_{t}^{H}-\tilde{u}_{t}^{F}$. Note that the unemployment differential is expressed in terms of the deviation from the efficient allocation, and thus any deviation from zero reflects inefficiencies in the adjustment process of the currency union.

Figure 2 shows the results of this exercise. A higher degree of UR increases the volatil-

\footnotetext{
${ }^{18}$ The effect of URs on $\gamma h_{T}$ is found to be negligible.
} 

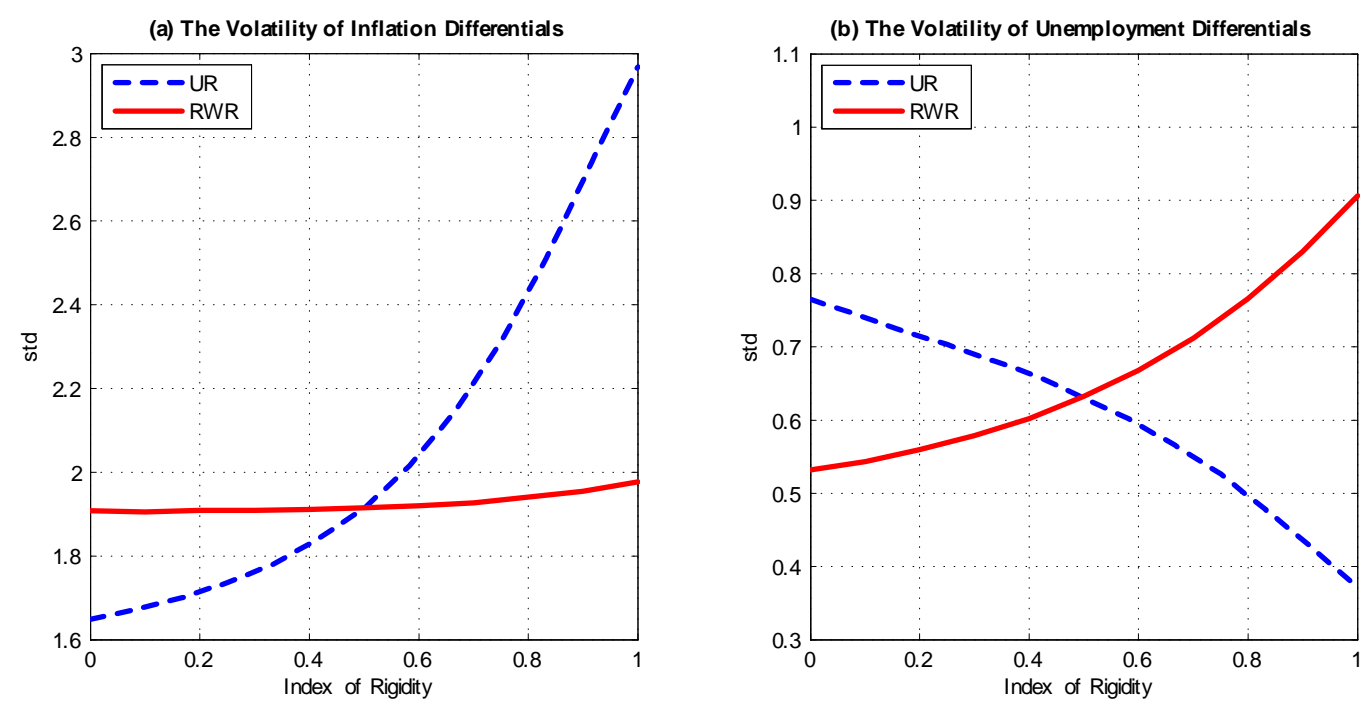

Figure 2: Labor Market Rigidities and the Volatility of Differentials

ity of the inflation differential, but reduces the volatility of the unemployment differential. Unemployment rigidities make it more costly for firms to hire new workers and induce firms to absorb shocks through an increase in prices. A higher degree of RWR, on the contrary, strongly increases the volatility of the unemployment differential, because, as in Hall (2005), wage rigidities increase the responsiveness of profits and thus hirings to shocks. The effect of real wage rigidities on the inflation differential is instead small and the slope is sensitive to calibration choices ${ }^{19}$.

Labor market rigidities are often blamed as one of the possible causes of large and longlasting inflation and unemployment differentials in the European Monetary Union. Our results, however, suggest that it is crucial to distinguish among the institutions that constrain the "quantity" adjustment (UR) from the ones that constrain the "price" adjustment (RWR) in the labor market, as these may have very different implications.

Result 1 (Labor Market Rigidities and the Volatility of Differentials): UR and $R W R$ have different effects on the volatility of inflation and unemployment differentials: UR increase the volatility of the inflation differential but reduce the volatility of the unemployment differential, while RWR increase the volatility of the unemployment differential but have little effect on the volatility of the inflation differential.

\footnotetext{
${ }^{19}$ As can be seen from Appendix Table A, the effect of RWR on the volatility of inflation differentials depends on the calibration of the model and the shock processes that hit the economy. In general, RWR have a small effect on the volatility of inflation differentials because they have two offsetting effects on marginal costs: on the one hand, they reduce the volatility of wages, but on the other hand, they increase the volatility of hiring, unemployment, labor market tightness and thus marginal hiring costs (i.e. the second component of the marginal cost equation (4); see Krause and Lubik (2007) for a thorough assessment of this issue in a closed economy setting).
} 

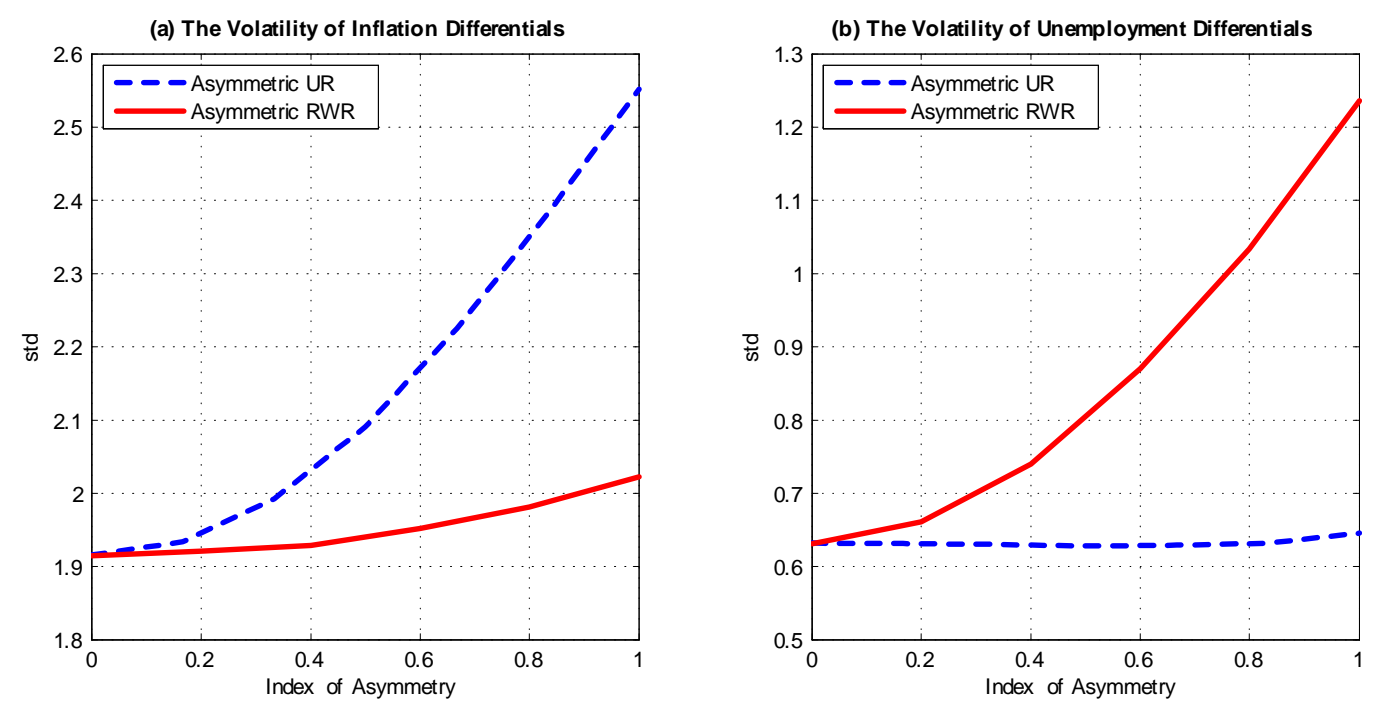

Figure 3: Asymmetric Labor Market Rigidities and the Volatility of Differentials

\subsection{The Importance of Asymmetries in Labor Market Rigidities}

We further analyze how labor market asymmetries affect the volatility of differentials, holding the average degree of UR and RWR constant. For this purpose, we construct an index of asymmetry that starts out at 0 where both countries are perfectly symmetric (the baseline calibration). As the index increases towards 1, the two countries become increasingly different but the average degree of UR and RWR does not change. ${ }^{20}$ The following tabulation shows the values of the underlying parameters:

\begin{tabular}{|l|c|c|}
\hline & Complete Symmetry: Index $=0$ & Strong Asymmetry: Index $=1$ \\
\hline \multirow{2}{*}{ Asymmetric UR } & $x^{H}=x^{F}=0.45$ & $x^{H}=0.2 / x^{F}=0.7$ \\
& $\delta^{H}=\delta^{F}=0.07$ & $\delta^{H}=0.03 / \delta^{F}=0.12$ \\
\hline Asymmetric RWR & $\gamma=\gamma^{*}=0.5$ & $\gamma=0.75 \quad / \quad \gamma^{*}=0.25$ \\
\hline
\end{tabular}

Figure 3 shows that the volatility of inflation and unemployment differentials is increasing in asymmetries in both UR and RWR. Asymmetries in the degree of real wage rigidity are found to increase substantially the volatility of the unemployment differential. Asymmetric unemployment rigidities have instead a stronger effect on the volatility of the inflation differential, which is related to the fact that in the presence of high UR firms adjust to shocks by adjusting prices rather than quantities. Overall, these results suggest that asymmetries in labor market structures worsen the adjustment of a currency union to shocks.

The reason for this result is simple and intuitive: when asymmetries are present, sym-

\footnotetext{
${ }^{20}$ See Benigno (2004) and Andersen and Seneca (2010) for similar assumptions.
} 
metric shocks are transmitted differently across member countries and, as a consequence, inflation and unemployment differentials arise. This result is remarkably robust as long as the correlation of shocks across countries is high enough. When the correlation of productivity and preference shocks is lower than in the baseline calibration, the volatility of differentials is still increasing, except for the volatility of the unemployment differential, which is slightly decreasing in the degree of asymmetry in UR. Notice, however, that it is likely that these shocks are more strongly correlated across members of the EMU than in our baseline calibration $\left(\rho_{\sigma_{a}}=0.258\right)$ because our baseline calibration is based on an estimate of $\rho_{\sigma_{a}}$ between the U.S. and a European aggregate (see Backus, Kehoe and Kydland, 1992).

Result 2 (Asymmetric Labor Market Rigidities and the Volatility of Differentials): Unless shocks are very weakly correlated across member countries, asymmetries in $U R$ and RWR increase the volatility of inflation and unemployment differentials in a currency union. This suggests that asymmetries in labor markets worsen the adjustment of a currency union to shocks.

\subsection{Interactions Between Labor Market Rigidities}

Table 2. The volatilities of the differentials and the interaction between asymmetries

\begin{tabular}{lcccc} 
Panel A: baseline & $\mathbf{s t d}(\pi \mathrm{d})$ & $\mathbf{s t d}\left(\mathbf{u}_{\mathrm{d}}\right)$ & $\mathbf{s t d}\left(\pi_{\mathrm{u}}\right)$ & $\mathbf{s t d}\left(\mathbf{u}_{\mathrm{u}}\right)$ \\
\hline Symmetric currency union & 1.91 & 0.63 & 1.54 & 0.67 \\
Asymmetric UR & 2.55 & 0.65 & 1.76 & 0.65 \\
Asymmetric RWR & 2.02 & 1.25 & 1.69 & 0.83 \\
Asymmetric UR + RWR (Complements) & 2.54 & 1.01 & 1.82 & 0.72 \\
Asymmetric UR + RWR (Substitutes) & 2.69 & 1.44 & 1.95 & 0.89 \\
\hline Panel B: simulations with perfectly correlated shock & $\mathbf{s t d}(\pi \mathrm{d})$ & $\mathbf{s t d}\left(\mathbf{u}_{\mathrm{d}}\right)$ & $\mathbf{s t d}(\pi \mathrm{u})$ & $\mathbf{s t d}\left(\mathbf{u}_{\mathrm{u}}\right)$ \\
\hline Symmetric currency union & 0.00 & 0.00 & 1.83 & 0.81 \\
Asymmetric UR & 1.41 & 0.36 & 1.98 & 0.78 \\
Asymmetric RWR & 0.68 & 1.29 & 2.01 & 0.99 \\
Asymmetric UR + RWR (Complements) & 1.38 & 1.01 & 2.05 & 0.86 \\
Asymmetric UR + RWR (Substitutes) & 1.68 & 1.58 & 2.22 & 1.05 \\
\hline \hline
\end{tabular}

Note: all series are unfiltered and inflation is annualized.

How important are interaction effects between different types of labor market rigidities? Panel A of Table 2 shows the volatility of inflation and unemployment differentials for a currency union characterized by asymmetries in both UR and RWR. The symmetric currency 
union follows the baseline calibration, whereas "Asymmetric UR" and "Asymmetric RWR" in rows 2 and 3 represent a currency union where the corresponding index of asymmetry is set to 1. The results confirm the Result 2 in the previous section. The rows 4 and 5 of Panel A study the interactions between asymmetries in UR and asymmetries in RWR, where "complements" characterizes a currency union where the home country has both low UR and low RWR (and, similarly, the foreign country has both high UR and high RWR). "Substitutes", on the other hand, characterizes a currency union where the home country has low UR and high RWR and the foreign country high UR and low RWR. The results show that when rigidities are complements at the country level, the volatility of inflation and unemployment differentials is somewhere in between the numbers of the currency union characterized by asymmetries in unemployment rigidities and the currency union characterized by asymmetries in real wage rigidity. In contrast, the adjustment mechanism of the currency union is much worse when labor market rigidities are substitutes at the country level, as the volatility of the inflation and the unemployment differential (as well as the volatility of the union variables) is higher than for any other economy. This suggests that when rigidities are substitutes, their effects tend to reinforce each other, whereas when they are complements the effects of asymmetries tend to offset each other.

Panel B further analyzes the results of simulations where we assume that all shocks are perfectly correlated across countries. As expected, the inflation and unemployment differential are zero at all times when the home and the foreign country are identical (the symmetric case). When the countries have asymmetric labor market structures, however, the volatility of these differentials increase dramatically. Moreover, when asymmetries are substitutes, the volatility of unemployment differentials is highest when shocks are perfectly correlated (i.e., compared to the corresponding numbers in Panel A). This is somewhat surprising as asymmetric shocks are completely absent here as a source of volatile differentials. Thus, if labor market institutions are asymmetric across countries, the costs of a currency union might be substantial even in the presence of highly correlated shocks across countries.

Result 3 (Interactions between Labor Market Rigidities): There are important interaction effects between asymmetries in UR and asymmetries in $R W R$ : when these rigidities are substitutes, their effects reinforce each other, whereas when they are complements their effects tend to offset each other.

\section{Conclusion}

This paper investigates how asymmetric labor market institutions affect the adjustment of a currency union to shocks. In our analysis, we focus on two types of labor market 
rigidities, Unemployment Rigidities (UR) and Real Wage Rigidities (RWR). The former capture institutions such as employment protection legislation, hiring costs and the matching technology that limit the flows in and out of unemployment, whereas the latter capture institutions that influence the responsiveness of real wages to economic activity. Three main conclusions emerge from our analysis:

First, the two types of labor market rigidities have very different effects on the incentives for firms to reset prices and thus on the Phillips curve. A higher degree of unemployment rigidities makes the Phillips curve steeper whereas real wage rigidities make the Phillips curve flatter. The basic intuition is that inflation is more sensitive to labor market conditions when firms adjust prices rather than quantities in response to shocks.

Second, labor market rigidities have a strong impact on the adjustment mechanism of the currency union to shocks. We find that unemployment rigidities increase the volatility of the inflation differential but reduce the volatility of the unemployment differential, while real wage rigidities increase the volatility of the unemployment differential and have little effect on the volatility of the inflation differential. Asymmetries in unemployment and real wage rigidities across countries, however, increase the volatility of both inflation and unemployment differentials, mainly because different labor market institutions lead to strong asymmetric responses to common shocks.

Finally, we study interaction effects between these two rigidities. We define rigidities as "complements" when unemployment and real wage rigidities are positively correlated at the country level, and as "substitutes" when they are negatively correlated at the country level. We find that the effects of the rigidities tend to offset each other when they occur in complements, but they reinforce each other when they are substitutes. This is an interesting result and further underlines the importance of distinguishing between different types of labor market rigidities.

Overall, our results suggest that asymmetries in labor market structures worsen the adjustment mechanism of a currency union to symmetric and asymmetric shocks. Therefore, it may be optimal to coordinate labor market reforms across the member countries of a currency union and to limit the degree of asymmetry in labor market rigidities. Another important consideration is that, in the presence of asymmetric labor market structures, monetary policy shocks themselves create terms of trade movements and are a source of differentials. The question then is whether the central bank can exploit these asymmetries and gain from responding systematically to differentials. Our model abstracts from a number of issues, such as imperfect insurance markets for unemployment risk, that make welfare comparisons and thus the derivation of the optimal policy difficult. Nevertheless, we think that these are important issues and we leave it to future research to tackle these questions. 


\section{References}

[1] Abbritti, M. and S. Weber (2010), "Labor Market Institutions and the Business Cycle: Unemployment Rigidities vs. Real Wage Rigidities", ECB Working Paper Series, n. 1183.

[2] Andersen, T. and M. Seneca (2010), "Labor Market Asymmetries in a Monetary Union", Open Economies Review, 21(4), 483-514.

[3] Angeloni, I. and M. Ehrmann (2004), "Euro Area Inflation Differentials", European Central Bank Working Paper Series, n. 388.

[4] Backus, D., P. Kehoe and F. Kydland (1992), "International Real Business Cycles", Journal of Political Economy, 100(4), 745-775.

[5] Benalal, N., J. Diaz del Hoyo, P. Benigno. and N. Vidalis (2006), "Output Growth Differentials across the Euro Area Countries. Some Stylised Facts", ECB Occasional Paper Series, n. 45.

[6] Benigno, P. and J. Lopez-Salido (2006), "Inflation Persistence and Optimal Monetary Policy in the Euro Area", Journal of Money, Credit and Banking, 38(3), 587-614.

[7] Benigno, P. (2004), "Optimal Monetary Policy in a Currency Area", Journal of International Economics, 63(2), 293-320.

[8] Blanchard, O. (2006), "European Unemployment: the Evolution of Facts and Ideas", Economic Policy, 21(45), 5-59.

[9] Blanchard, O. and J. Galí (2007), "Real Wage Rigidities and the New Keynesian model", Journal of Money, Credit, and Banking, supplement to vol. 39(1), 35-66.

[10] Blanchard, O. and J. Galí. (2010), "Labor Markets and Monetary Policy: A New Keynesian model with Unemployment", American Economic Journal - Macroeconomics, 2, 1-30.

[11] Calvo, G. (1983), "Staggered Prices in a Utility-Maximizing Framework", Journal of Monetary Economics, 12(3), 383-398.

[12] Campolmi, F. and E. Faia (2011), "Labor Market Institutions and Inflation Volatility in the Euro Area", Journal of Economic Dynamics and Control, 35(5), 793-812.

[13] Christoffel, K., K. Kuester and T. Linzert (2009), "The Role of Labor Markets for Euro Area Monetary Policy", European Economic Review, 53(8), 908-936.

[14] Dellas, H. and G. Tavlas (2005), "Wage Rigidity and Monetary Union", Economic Journal, 115(506), 907-927.

[15] ECB (2003), "Inflation Differentials in the Euro Area: Potential Causes and Policy Implications", ECB Report, September 2003.

[16] ECB (2005), "Monetary Policy and Inflation Differentials in a Heterogeneous Currency Area", ECB Monthly Bulletin, May 2005, pp. 61-77.

[17] EEAG (2007), The EEAG Report on the European Economy, CESifo, Munich.

[18] Galí, J. and T. Monacelli (2008), "Optimal Monetary and Fiscal Policy in a Currency Union", Journal of International Economics, 76(1), 116-132. 
[19] Fahr, S. and F. Smets (2010), "Downward Wage Rigidities in a Monetary Union with Optimal Monetary Policy", The Scandinavian Journal of Economics, 112(4), 812-840.

[20] Hall, R. (2005), "Employment Fluctuations with Equilibrium Wage Stickiness", American Economic Review, 95(1), 50- 65.

[21] Krause, M. and T. Lubik (2007), "The (Ir)relevance of Real Wage Rigidity in the New Keynesian Model with Search Frictions", Journal of Monetary Economics, 54(3), 707-726.

[22] Krause, M, D. Lopez-Salido and T. Lubik (2008a), "Inflation Dynamics with Search Frictions: A Structural Econometric Analysis", Journal of Monetary Economics, 55(5), 892-916.

[23] Krause, M, D. Lopez-Salido and T. Lubik (2008b), "Do Search Frictions Matter for Inflation Dynamics?", European Economic Review, 52(8), 1464-1479.

[24] Nickell, S. (1997), "Unemployment and Labor Market Rigidities: Europe versus North America", Journal of Economic Perspectives, 11(3), 55-74.

[25] Nickell, S., L. Nunziata, W. Ochel and G. Quintini (2001), "The Beveridge Curve, Unemployment and Wages in the OECD", CEP Discussion Paper, n. 502.

[26] Mortensen, D. and C. Pissarides (1994), "Job Creation and Job Destruction in the Theory of Unemployment", Review of Economic Studies, 61(3), 397-415.

[27] Poilly, C. and J.-G. Sahuc (2008), "Welfare Implications of Heterogeneous Labor Markets in a Currency Area", mimeo, Banque de France.

[28] Ravenna, F. and C. Walsh (2008), "Vacancies, Unemployment and the Phillips Curve", European Economic Review, 52(8), 1494-1521.

[29] Ravenna, F. and C. Walsh (2010), "The Welfare Consequences of Monetary Policy and the Role of the Labor Market", American Economic Journal - Macroeconomics, forthcoming.

[30] Sahuc, J.G. and F. Smets (2008), "Differences in Interest Rate Policy at the ECB and the Fed: An Investigation with a Medium-Scale DSGE Model", Journal of Money, Credit and Banking, 40(2-3), 505-521.

[31] Shimer, R. (2005), "The Cyclical Behavior of Equilibrium Unemployment and Vacancies", American Economic Review, Vol. 95, Issue 1, pp. 25-49.

[32] Smets, F. and R. Wouters (2003), "An Estimated Dynamic Stochastic General Equilibrium Model of the Euro Area", Journal of the European Economic Association, 1(5), 1123-1175.

[33] Thomas, C. (2008), "Search and Matching Frictions and Optimal Monetary Policy", Journal of Monetary Economics, 55(5), 936-956.

[34] Thomas, C. and F. Zanetti (2009), "Labor Market Reform and Price Stability: an Application to the Euro Area", Journal of Monetary Economics, 56(6), 885-899.

[35] Walsh, C. (2005), "Labor Market Search, Sticky prices, and Interest Rate Policies", Review of Economic Dynamics, 8(4), 829-849.

[36] Zanetti F. (2010), "Labor Market Institutions and Aggregate Fluctuations in a Search and Matching Model", European Economic Review, forthcoming. 


\section{Appendix}

Appendix Table A. The volatilities of the differentials: robustness checks for the symmetric case

\begin{tabular}{|c|c|c|c|c|}
\hline Panel A: baseline calibration & $\operatorname{std}\left(\pi_{d}\right)$ & $\operatorname{std}\left(u_{d}\right)$ & $\operatorname{std}\left(\pi_{\mathrm{u}}\right)$ & $\operatorname{std}\left(u_{u}\right)$ \\
\hline Baseline & 1.91 & 0.63 & 1.54 & 0.67 \\
\hline High RWR & 1.97 & 0.91 & 2.41 & 1.53 \\
\hline High UR & 2.97 & 0.37 & 2.11 & 0.50 \\
\hline Panel B: simulations with $\sigma=3$ & $\operatorname{std}\left(\pi_{d}\right)$ & $\operatorname{std}\left(u_{d}\right)$ & $\operatorname{std}\left(\pi_{\mathbf{u}}\right)$ & $\operatorname{std}\left(u_{u}\right)$ \\
\hline Baseline & 1.99 & 0.58 & 1.61 & 0.38 \\
\hline High RWR & 2.04 & 0.79 & 2.38 & 0.92 \\
\hline High UR & 3.33 & 0.35 & 3.24 & 0.35 \\
\hline Panel C: simulations with fi=3 (disutility of labor) & $\operatorname{std}\left(\pi_{d}\right)$ & $\operatorname{std}\left(u_{d}\right)$ & $\operatorname{std}\left(\pi_{\mathbf{u}}\right)$ & $\operatorname{std}\left(u_{u}\right)$ \\
\hline Baseline & 2.10 & 0.44 & 1.46 & 0.37 \\
\hline High RWR & 2.03 & 0.62 & 1.73 & 0.78 \\
\hline High UR & 2.98 & 0.25 & 2.01 & 0.26 \\
\hline Panel D: simulations with only preference shocks & $\operatorname{std}\left(\pi_{d}\right)$ & $\operatorname{std}\left(u_{d}\right)$ & $\operatorname{std}\left(\pi_{\mathbf{u}}\right)$ & $\operatorname{std}\left(u_{u}\right)$ \\
\hline Baseline & 0.52 & 0.28 & 0.40 & 0.15 \\
\hline High RWR & 0.41 & 0.37 & 0.35 & 0.17 \\
\hline High UR & 0.90 & 0.14 & 0.73 & 0.07 \\
\hline Panel E: simulations with only productivity shocks & $\operatorname{std}\left(\pi_{d}\right)$ & $\operatorname{std}\left(\mathbf{u}_{d}\right)$ & $\operatorname{std}\left(\pi_{\mathbf{u}}\right)$ & $\operatorname{std}\left(u_{u}\right)$ \\
\hline Baseline & 1.84 & 0.56 & 1.22 & 0.57 \\
\hline High RWR & 1.93 & 0.83 & 2.27 & 1.48 \\
\hline High UR & 2.83 & 0.35 & 1.19 & 0.47 \\
\hline Panel F: simulations with only monetary policy shocks & $\operatorname{std}\left(\pi_{d}\right)$ & $\operatorname{std}\left(u_{d}\right)$ & $\operatorname{std}\left(\pi_{\mathbf{u}}\right)$ & $\operatorname{std}\left(u_{u}\right)$ \\
\hline Baseline & 0.00 & 0.00 & 0.85 & 0.32 \\
\hline High RWR & 0.00 & 0.00 & 0.74 & 0.37 \\
\hline High UR & 0.00 & 0.00 & 1.58 & 0.16 \\
\hline Panel G: simulations with only mark up shocks & $\operatorname{std}\left(\pi_{d}\right)$ & $\operatorname{std}\left(\mathbf{u}_{d}\right)$ & $\operatorname{std}\left(\pi_{\mathrm{u}}\right)$ & $\operatorname{std}\left(u_{u}\right)$ \\
\hline Baseline & 0.36 & 0.36 & 0.38 & 0.26 \\
\hline High RWR & 0.44 & 0.45 & 0.55 & 0.39 \\
\hline High UR & 0.21 & 0.26 & 0.25 & 0.19 \\
\hline
\end{tabular}

Note: all series are unfiltered and inflation is annualized. Marginal cost shocks can be introduced easily by modelling them as shocks to the elasticity of substitution between varieties. The standard deviation for marginal cost shocks is assumed to be 0.3 , which is well above the 0.164 in Smets and Wouters (2003). We assume an autocorrelation coefficient of 0.85 for these shocks. 
Appendix Table B. The volatilities of the differentials: robustness checks for the asymmetric case

Panel A: simulations with $\sigma=3$

$\operatorname{std}\left(\pi_{d}\right)$

$\operatorname{std}(\mathbf{u d})$

$\operatorname{std}\left(\pi_{u}\right)$

$\operatorname{std}(\mathbf{u} \mathbf{)}$

Symmetric currency union

1.99

0.58

1.61

0.38

Asymmetric UR

3.12

0.51

2.09

0.37

Asymmetric RWR

2.12

1.19

1.72

0.47

Asymmetric UR + RWR (Complements)

3.12

1.01

2.05

0.41

Asymmetric UR + RWR (Substitutes)

3.22

1.29

2.28

0.51

Panel B: simulations without preference shocks

Symmetric currency union

$\operatorname{std}(\pi d)$

Asymmetric UR

1.84

$\operatorname{std}(\mathbf{u d})$

$\operatorname{std}(\pi \mathrm{u})$

0.56

1.49

$\operatorname{std}(\mathrm{uu})$

Asymmetric RWR

2.41

0.58

1.69

0.66

Asymmetric UR + RWR (Complements)

1.96

1.21

1.64

0.64

Asymmetric UR + RWR (Substitutes)

2.40

0.97

1.74

0.82

RWR (Substitutes)

2.57

1.41

1.88

0.71

2.57

1.41

$\operatorname{std}(\pi d)$

$\operatorname{std}(u d)$

Symmetric currency union

\begin{tabular}{llll}
1.95 & 0.73 & 1.59 & 0.72 \\
2.58 & 0.74 & 1.80 & 0.70 \\
2.06 & 1.31 & 1.74 & 0.88 \\
2.57 & 1.06 & 1.86 & 0.76 \\
2.73 & 1.52 & 1.99 & 0.94 \\
\hline
\end{tabular}

Asymmetric UR

nal cost shocks

Asymmetric RWR

0.88

Note: all series are unfiltered and inflation is annualized. Marginal cost shocks can be introduced easily by modelling them as shocks to the elasticity of substitution between varieties. The standard deviation for marginal cost shocks is assumed to be 0.3 , which is well above the 0.164 in Smets and Wouters (2003). We assume an autocorrelation coefficient of 0.85 for these shocks. 